usually dealt with in books devoted to chest disease, but is certainly worthy of inclusion.

The chapter on lesions of the diaphragm is perhaps the least admirable in the book; the account of diaphragmatic hernia is below the general standard of this book. In presenting industrial diseases of the lungs Dr. Ellman once more reaches the high standard which he has set himself and all aspects of this dreaded disease of miners are dealt with.

The book is exceedingly well illustrated with $\mathrm{X}$-ray photographs, line drawings and photographs of post-mortem specimens. In a book of this kind it is important that the quality of the illustrations should be of high standard and we congratulate the publishers on attaining such a standard. The book is written in a pleasant, easily readable style and the index is adequate.

\section{OBSTETRICAL PRACTICE}

By Alfred C. Beck, M.D. 5th Edition. Pp. xiv + ro73, with 969 illustrations. London: Baillière, Tindall and Cox. r951. 76s. 6d. net.

This well-known American textbook was written in 1935 and its popularity required two reprints of the 4 th edition which appeared in 1947 , while there has also been a Spanish and a Portuguese edition. The greater part of this new edition has been rewritten with 106 new illustrations and an appendix of 22 excellent X-ray plates.

'The purpose of the book is to present the essentials of obstetrical practice to undergraduates, students and young practitioners,' and in this it certainly succeeds. The most striking thing about the book is the profusion of beautiful pen drawings which have mostly been drawn by the author himself. They are used to very good effect, and series of drawings illustrate the steps of procedures without a lengthy description. Famous names in obsterical history are also illustrated with a few remarks about each.

There is an orthodox arrangement of chapters and full use is made of sub-headings and summaries to simplify the text which is clearly written. In particular there are excellent accounts of the physiology of the placenta and also of the mother in pregnancy. A very adequate index and a long list of references at the end of each chapter greatly increase the value of this book.

This textbook achieves its object in giving a clear, straightforward account of obstetrical practice, but the postgraduate in Britain will find little that is new.

\section{CLINICAL RADIOLOGY OF THE EAR, NOSE AND THROAT}

By ERIC SAMUEL, M.D., F.R.C.S., F.F.R., D.M.R.E. Pp. viii + 339. London: H. K. Lewis \& Co., Ltd. 1952. 70s. net.

This book bears the unmistakable stamp of authority. It is obviously primarily intended as a reference book for diagnostic radiologists but willat the same time, be of great value to otorhino, laryngologists.
Strongly and pleasantly bound the text is clear and easy to follow and it is profusely illustrated. Most of the positive X-ray plates are a delight, the paranasal sinus plates being particularly clear. The text is very detailed as behoves a book of reference and the author quotes his references chapter by chapter. There is a handy index and also an index to authors which will prove valuable for tracing cross references. This book should certainly belong in the libraries of radiologists and E.N.T. surgeons.

DISEASES OF THE EAR, NOSE AND THROAT

By G. Portmann, M.D. Pp. vii +782 , with 666

illustrations. London: Baillière, Tindall \& Cox. 1951. £7 ros. net.

This volume would be better named 'Clinical Methods in E.N.T. Surgery '-it is not a description of the diseases of the ear, nose and throat. It is beautifully produced but far too long-some 700 pages confined to descriptions of the anatomy and physiology of, and practical methods used for diagnostic examination of the ear, nose and throatwhich seems to be making much ado about little. There are over 600 illustrations, most of them helpful to the text and very clear; some, however, do not have the notes translated from the French. There are no references.

\section{THE RH BLOOD GROUPS AND THEIR CLINICAL EFFECTS}

Medical Research Council, Memorandum No. 27 (Revision of Memorandum No. 19).

By P. L. Mollison, M.D., M.R.C.P., A. E? Mourant, D.Phil., D.M., and R. R. Race, Ph.D., M.R.C.S. Pp. vi +72 . London: H.M. Stationery Office. 1952. 3s. net.

This Memorandum is likely to be as widely read and used as was its valuable predecessor, Memorandum No. 19, of which it is a new edition. Its size has, however, not been increased. The text of the sections on 'Clinical Considerations' by P. L. Mollison and on ' Rh Testing' by A. E. Mourant has been thoroughly revised and is now up to date and authoritative. R. R. Race's section on the $\mathrm{Rh}$ Groups is largely unaltered, but as an introduction to the intricasies of the subject it still serves its purpose adin: rably.

J.V.D.

\section{CAUSES AND PREVENTION OF TUBERCULOSIS}

By Brice R. Clarke, M.D. Pp. viii +288 , with 15 illustrations. Edinburgh: E. \& S. Living stone, Ltd. 1952. 32s. 6d.

In these days when so much attention is being focussed on diagnosis and treatment it is refreshing to find a book devoted entirely to the causes and prevention of tuberculosis. The work covers'a wide field and pays special attention to primary tuberculosis and the subsequent development of active disease. There is an excellent chapter on Food and Tuberculosis, and the sections dealing specifically 
with prevention are of great practical value. There are special chapters on bovine tuberculosis in man, mass miniature radiography and immunization against tuberculosis.

Looking into the book in more detail one finds that the author has spared no pains to support his argument by a full survey of the literature on the aspects of the subject dealt with in the respective chapters. This extensive bibliography at the end of each chapter makes the book very valuable for reference. The author has also been able, from his own wide experience, to make authoritative statements on debatable subjects. On the influence of race and heredity he favours the existence of familial susceptibility or resistance, but thinks it present in only a small proportion of persons of European stock.

He stresses the need for diagnoses in the preclinical stage of the disease before the development of cavitation or apical infiltration which are signs of late advanced tuberculosis.

An open mind is kept on the vexed question of endogenous and exogenous infection. The subject is fully discussed under the four headingstuberculosis in contacts, in specially exposed persons, in persons specially subjected to overcrowding and in the study of the results of measures taken to control infection.

The general conclusion is that super infection is a factor of considerable importance in determining the clinical history subsequent to the primary infection.

The chapter on food and tuberculosis is well worth careful study, and although no final conclusions are reached a high protein diet is favoured and research is suggested on the value of such a diet in the presence of a positive $\mathrm{N}$ balance and on its influence on the blood protein pattern in cases of active tuberculosis.

It is interesting to note that when discussing the influence of environment on the development of active disease it is stated that 'Provision of an adequate food supply is far the most important of living conditions in relation to tuberculosis, because the almost universal latent infection will manifest itself as disease in proportion to the severity of malnutrition. Other living conditions are important either as contributory causes of malnutrition or as factors which predispose to infection.' These are probably two of the most important sentences in the book.

Mass radiography is dealt with by Dr. J. Ritchie in a short chapter that contains much information of practical value. It is good to be reminded that accuracy rather than speed should be the paramount consideration, and it is comforting to read that in mass radiography the emphasis 'has again been placed-where it rightly rests-on the prevention of tuberculosis.' The linking up of tuberculin testing, B.C.G. vaccination and mass radiography is also favoured.

Immunization against tuberculosis is given a chapter to itself, which is rather sketchy and incomplete.
More could have been said on the administrative $\frac{2}{2}$ side of B.C.G. vaccination as a preventive measure and the need or otherwise of segregation of persons $\stackrel{a}{c}$ suitable for vaccination.

In a book of this type it would be unusual if there $\vec{F}$ were no omissions. One would have liked to have seen more reference to education as a means of prevention, to the control of tuberculosis among food handlers and to the risks that healthy children $\frac{\rho}{5}$ run of contracting the disease in schools and other $\stackrel{\mathbb{Q}}{\circ}$ institutions, but a work that covers every aspect of the cause and prevention of tuberculosis would ${ }^{\infty}$ comprise many volumes, and it is remarkable how $\overrightarrow{0}$ much information Dr. Clarke has included in this volume of 288 pages, which has been well indexed $\vec{\sigma}$ and excellently produced.

The book should be read by all chest physicianso and medical officers of health as well as postgraduate 3 . students of phthisiology.

F.H.

\section{ENDOSCOPY}

By EDWARD B. BENEDICT, A.B., M.D., F.A.C.S., Шे with foreword by EDward D. ChURChill. Pp. $\frac{1}{2}$ xiv +373 , with 142 illustrations, 12 in colour. 을 London: Ballière Tindall \& Cox. I 95 I. 76s. 6d. -

There is no doubt that Dr. Benedict has carefully $\subseteq$ compiled and illustrated his book and has rendered an unusual service to medical men interested in $\vec{P}$ thoracic and abdominal diseases. As Dr. Churchip of remarks in the foreword, he has considered he $N$ findings from the clinical standpoint in spite of a temptation merely to exercise a skill in technique He has thus achieved a correlated account of bronchoscopy, oesophagoscopy, gastroscopy and peritoneoscopy which will be helpful both to the established specialist and to the student whose $\stackrel{\mathbb{Q}}{2}$ future will accept endoscopy as a matter of course. $\overrightarrow{\vec{A}}$ The historical account of the subject indicates how 3 fast it is leaving the hands of the laryngologists to be adopted by thoracic or abdominal specialists.

Dr. Benedict is rightly unique in his work and his services as a teacher. There can be room for $\frac{0}{3}$ but few pure endoscopists. In England, it would be rare to find a surgeon willing to design his $\frac{5}{3}$ operation upon the findings of another man without. also seeing for himself. Yet it is difficult for himo to learn skillful technique-such for instance as is required in a difficult oesophagoscopy, and it iso almost impossible for any one man to see personally during his training a sufficient variety of lesions to be able to diagnose them with certainty.

The advocacy of local anaesthesia for broncho- $N$ scopy is generally accepted, but with the advent of the relaxant drugs it is probable that the con- 0 sequent ease of passage of the oesophagoscope ${ }_{\omega}^{N}$ provides a valuable safety factor in the hands of the less experienced, especially in difficult cases It will perhaps surprise British doctors that the rather narrow parallel-sided Jackson bronchoscope and oesophagoscope should still be preferred to ${ }^{-}$ the graded more capacious Negus instruments in $\frac{0}{\circ}$ common use in England. Moreover, no mention $\frac{\vec{\Phi}}{\mathrm{D}}$ is made of the high-power oesophageal telescope 